\title{
A new method of full thickness skin graft fixation
}

\author{
H. K. MEHTA \\ From the Department of Ophthalmology, Caernarvonshire and Anglesey General Hospital, Bangor
}

SUMMARY A technique of free full thickness skin graft fixation utilising central and paracentral sutures between the graft and the depths of the recipient bed is described. The intrinsic fixation provided by these sutures allows larger free grafts, thus eliminating the need to use local flaps. These sutures also allow double free grafts-mucosal and dermal-for full thickness lower eyelid reconstructions. Patients do not need hospital admission and can resume normal activity immediately after the operation. One hundred and nine skin grafts secured by this technique have yielded very satisfactory results.

All methods currently employed to secure a full thickness skin graft to the recipient bed utilise the technique of the tie-over bolus. A firm pressure bandage is usually applied for the first few days to reinforce the stability of the graft. To ensure that the graft is not lifted off its bed by formation of haematoma under it, such patients are usually admitted to hospital so that their activity after the operation can be restricted for about a week. The aim of this communication is to describe and evaluate a new technique which in addition to the usual marginal sutures utilises central and paracentral sutures (in principle similar to the standard surgical practice of 'quilting' of large split-skin grafts in concave areas) to transfix full thickness skin grafts in oculoplastic surgery.

\section{Patients and methods}

One hundred and nine consecutive and unselected patients treated in my unit for oculoplasty with full thickness skin grafts between January 1973 and June 1977 have been included in this study. The size of the skin grafts varied between 1.2 and $3.5 \mathrm{~cm}$ in the longest diameter. The follow-up period ranged from 6 months to $4 \frac{1}{2}$ years.

Eighty-seven cases were treated for malignant or suspected malignant tumours; 14 of these in addition to a free skin graft needed a mucosal graft for full thickness lower eyelid reconstruction; 15 cases were treated for correction of lower eyelid ectropion, and 7 cases for xanthelasma. All grafts were secured by $5-0$ polyglycolic acid sutures (Dexon) by a technique

Address for reprints: H. K. Mehta, FRCS, Derwen Deg, Bangor, Gwynedd, Wales briefly outlined previously (Mehta, 1977) and fully described here. The surgery was carried out under local anaesthesia as day cases except for 5 patients who were admitted to the hospital for social reasons. Tie-over bolus was not used in any of these 109 patients.

In the past 12 months the firm pressure bandage dressing has not been used in 14 grafts that were so situated as to be able to be covered by a cartella shield without the edge of the shield pressing on any part of the graft. To soak up any oozing blood eye pads were used on the superficial aspect of the shield, which was kept in situ with a bandage till the first dressing 48 hours later. Two of these 14 patients had ectropion of the lower eyelid of their only functional eye. These 2 patients were also treated as day cases. A large central hole was made in a cartella shield, which was the sole 'dressing' for these 2 skin grafts. The shield was kept in situ till the removal of central and marginal sutures on the 7 th postoperative day.

All patients were given 2 co-trimoxazole tablets twice daily for 5 days. They were called to the hospital for the first dressing 48 hours after the operation, and were next seen on the 7th or 9th postoperative day for removal of all sutures. The subsequent clinic visits were at progressively doubled intervals till an annual follow-up period was obtained. They are then seen annually.

\section{SURGICAL TECHNIQUE}

Full thickness skin graft is obtained from the retroauricular sulcus or from the inner arm-allowance must be made for shrinkage of the graft. Subcutaneous fat of the graft is snipped off with scissors. The graft is now placed into the prepared recipient bed. One long edge of the graft is sutured with 


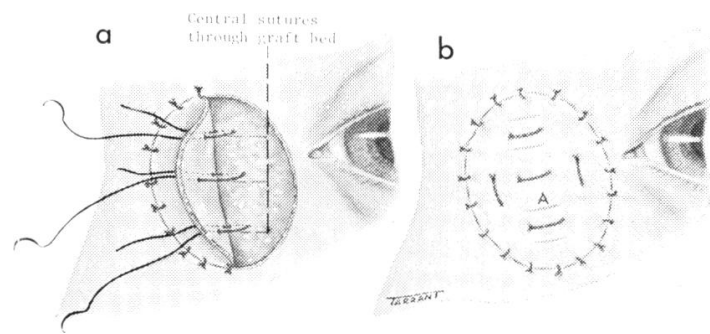

Fig. 1 Author's technique of full-thickness skin graft fixation using marginal and 'central' sutures of 5-0 polyglycolic acid (Dexon). Reproduced from Mehta (1977)

interrupted marginal sutures of 5-0 polyglycolic acid (Dexon) placed 2 or $3 \mathrm{~mm}$ apart. Central and paracentral sutures of 5-0 Dexon are now passed between the graft and the depth of the recipient bed (Fig. 1a). At least 4 such sutures are passed. For a large graft many additional sutures in 2 or more circles concentric with the graft edge are required. These 'central' sutures are not tied until after the remaining marginal sutures have been introduced and tied. The 'central' sutures are now tied under moderate tension to allow and maintain proper approximation between the graft and the recipient bed (Fig. 1b). A tie-over bolus is not necessary. A firm pressure dressing bandage is also not absolutely necessary.

\section{Results}

There was a $100 \%$ 'take' of the graft in all 109 patients. The usual transition of the colour of the graft from blotchy blue to healthy pink was observed in all cases between the $3 \mathrm{rd}$ and the 8th postoperative day. In one case of an 86-year-old woman (Fig. 2), there is a poor colour match of the graft obtained from the inner arm. She needed full thickness reconstruction of over three-quarters of the lower eyelid. The repair was carried out with free buccal mucosal and simultaneous free skin graft. This was one of my earlier cases, wherein the central sutures were much less numerous than the number of sutures I now introduce. The remaining 108 patients have grafts that have good colour match, texture, surface regularity, and pliability (Fig. 3).

\section{Discussion}

Of the many requisites for successful skin grafting apart from surgical competence-perhaps the most important single factor to ensure a good 'take' is the maintenance of a firm and constant approximation between the graft and the recipient bed for the first postoperative week. It is equally important to immobilise the graft in its bed to prevent the formation of haematoma by avulsion of the newly sprouting fronds of fragile vascular tissue. One of the main causes of failure of a free graft is the formation of haematoma underneath it.

All methods of securing free full-thickness grafts to the recipient bed as currently practised by various oculoplastic surgeons utilise the principle of continued impaction of the graft to its bed by an extrinisic mechanical device-for example, cottonwool bolus, Teflon roll, sponge, stent, tinfoil, or other conformers-retained by tie-over sutures (Mustardé, 1966; Mustardé et al., 1970; Fox, 1976; Reeh et al., 1976; Smith, 1976; Soll, 1976; Tenzel, 1976). Such fixation devices are helpful on convex surfaces. But on concavites, for example, the medical canthus and surrounding area (where the majority of basal cell tumours occur), and especially the sites where there is no rigid skeleton against which external pressure can be exerted, for example, in full thickness reconstructions of lower eyelids with double free grafts, external fixation devices cannot be relied on. A further drawback to these fixation devices is the need to admit patients to the hospital, so that their activity after the operation can be restricted. The larger the graft, the more the restrictions.

It would appear that the ideal technique for fixation of a free graft should provide intrinsic fixation-an intraoperative transfixion that can be maintained until cuto-cutaneous union occurswithout any reliance on external factors to maintain the graft-to-bed approximation. These criteria are fulfilled by the central and paracentral sutures described in my technique (Fig. 1).

This central fixation technique would appear to have the following advantages over the tie-over bolus technique: (1) Free dermal grafts of much larger size can be utilised, thus eliminating the need to use local pedicle flaps, which have their disadvantages. (2) Grafts of irregular shapes in awkward sites like the nasocanthal region or the outer canthus can be utilised with excellent results. (3) Assured constant approximation and immobility of the graft relative to its bed prevents a gap that would otherwise be filled by haematoma and fibroblastic invasion. The ultimate results are therefore of a consistently good quality. (4) As there is no need to restrict the activity of the patient after the operation, surgery can be performed on day case basis.

The theoretical objections that may be raised about this technique are that the central sutures may provoke a foreign body reaction resulting in formation of granuloma in the recipient bed, or that they may provide a track for epithelial cells to migrate to the recipient bed and thus put the graft 
in jeopardy. Neither of these phenomena have been encountered in any of the 109 patients reviewed for this communication.

So far as the suture material is concerned, after extensive experience I have come to regard 5-0 polyglycolic acid suture material (Dexon) as the

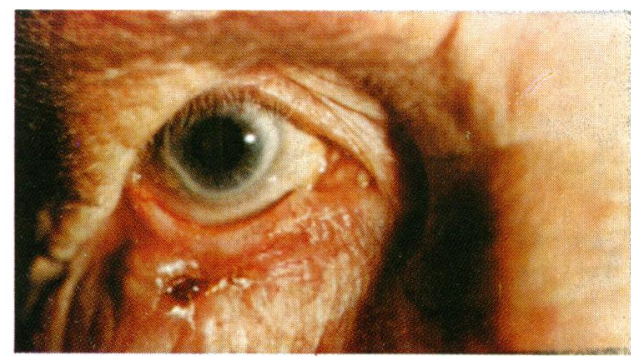

$2 a$

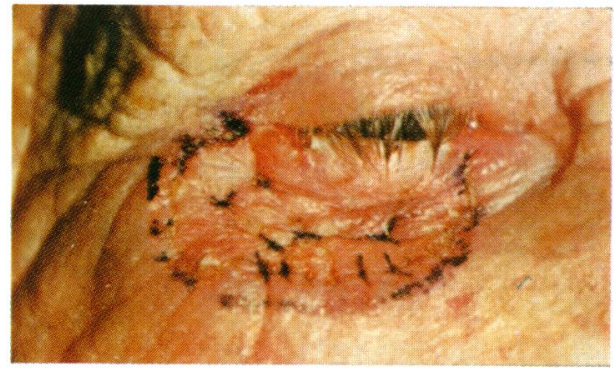

$2 b$

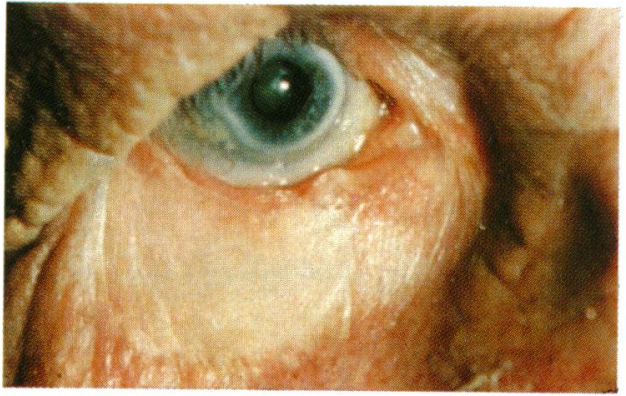

$2 c$

Fig. 2 Rodent ulcer involving the right lower eyelid of an 86-year-old female. Nearly three-quarters of the lower eyelid was excised in full-thickness, and the reconstruction carried out with free buccal mucosal and free skin graft. Note absence of 'central' sutures near lid margin, and also that the central sutures are not so numerous as I now insert. Paucity of central sutures has resulted in less than satisfactory end result-there is sagging of the new lid margin, and poor colour match of the graft.

(a) Preoperative. (b) Immediate postoperative.

(c) Appearance 9 months after surgery most suitable among those currently available, but think that a thinner suture (6-0) of Dexon on a similar needle $(11 \mathrm{~mm}$, three-eights circle) would perhaps be more suitable. The advantage of Dexon over silk is that Dexon is better able to hold the wound edges, as the knots do not slip. However, the

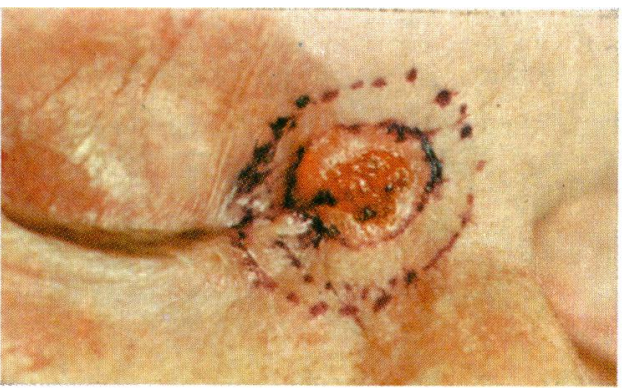

$3 a$

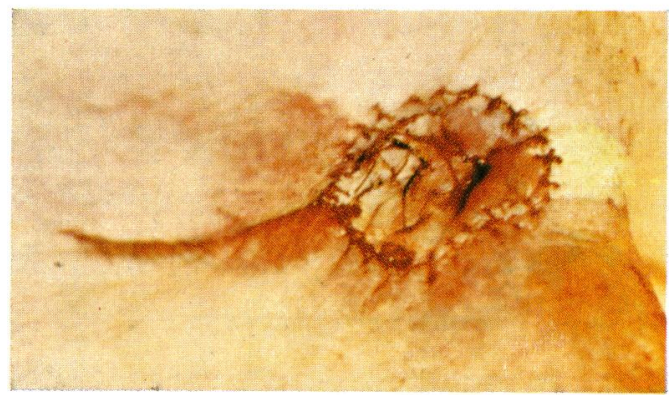

$3 b$

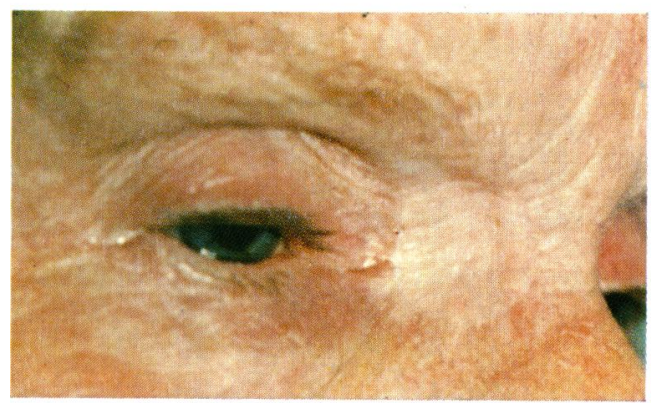

$3 c$

Fig. 3 (a) Preoperative appearance of rodent ulcer at the inner canthus. Proposed excision along the outer markings. (b) Immediate postoperative appearance showing the marginal and central sutures securing the graft. (c) Appearance 6 months after surgery, showing a satisfactory graft with good colour match, texture and surface 
disadvantage of Dexon is that the sutures are a little more difficult to remove than the silk sutures. Their removal is best achieved with the heel of a No. 15 Bard-Parker blade.

\section{References}

Fox, S. A. (1976). Ophthalmic Plastic Surgery, 5th edn., p. 90. Grune \& Stratton: New York.

Mehta, H. K. (1977). Assessment of major intraocular and extraocular surgery performed as day cases. Transactions of the Ophthalmological Societies of the United Kingdom, 97, 117-123.

Mustardé, J. C. (1966). Repair and Reconstruction in the Orbital Region, 1st edn., p. 360. Livingstone: Edinburgh and London.
Mustardé, J. C., Jones, L. T., and Callahan, A. (1970). Ophthalmic Plastic Surgery Up-to-date, 1st edn., p. 141. Aesculapius Publishing Co.: Birmingham, Alabama.

Reeh, M. J., Beyer, C. K., and Shannon, G. M. (1976). Practical Ophthalmic Plastic and Reconstructive Surgery, 1st edn., pp. 69, 127. Lea \& Febiger: Philadelphia.

Smith, B. (1976). In Management of Complications in Ophthalmic Plastic Surgery, edited by D. B. Soll, 1st edn., p. 243. Aesculapius Publishing Co.: Birmingham, Alabama.

Soll, D. B. (1976). In Management of Complications in Ophthalmic Plastic Surgery, edited by D. B. Soll, 1st edn., pp. 197-199. Aesculapius Publishing Co.: Birmingham, Alabama.

Tenzel, R. R. (1976). In Management of Complications in Ophthalmic Plastic Surgery, edited by D. B. Soll, 1st edn., p. 127. Aesculapius Publishing Co.: Birmingham, Alabama. 